Artigo Original

\title{
Educação Significativa como Prática de Estágio
}

\section{Curricular}

\author{
Meaningful Education as Curricular Internship Practice
}

\author{
Beatriz Fagundes Bica' ${ }^{1}$ e Cristiane Medianeira da Silva Reis ${ }^{2}$
}

1. Pedagoga. Pós-graduada em Gestão Educacional pela Universidade Federal de Santa Maria (UFSM).

Professora e coordenadora Pedagógica da Rede de Ensino do Município de Santa Maria, RS.

2. Pedagoga. Pós-graduada em Gestão Educacional (UFSM). Mestre em Educação (UFSM). Doutora pela

UFSM. Professora e coordenadora Pedagógica da Rede de Ensino do Município de Santa Maria, RS.

_beatrizbica@yahoo.com.br e crysreys@yahoo.com.br

\section{Palavras-chave \\ Autobiografia \\ Gêneros textuais \\ Prática pedagógica}

\section{Keywords}

Autobiography

Textual genres

Pedagogical practice
Artigo recebido em: 12.03.2021.

Aprovado para publicação em: 31.03.2021.

\begin{abstract}
Resumo:
O presente artigo refere-se a uma prática de estágio desenvolvida no último semestre do curso de graduação em Letras, Português e Literaturas - EAD de uma Universidade Federal da região Sul do Brasil, no ano de 2020. A temática abordada discorre sobre a relevância do trabalho com gêneros textuais. Neste sentido, objetiva-se com este estudo uma reflexão da prática pedagógica, desenvolvida com alunos do $3^{\circ}$ Ano do Ensino Médio noturno, de uma Escola Estadual de Ensino Médio, situada ao sul do Brasil. Tais experiências e vivências buscamos, respostas para a problemática deste estudo: Qual a relevância do trabalho com Gêneros textuais em sala de aula? Esse estudo é realizado usando como método um relato de prática de estágio perpassando a abordagem qualitativa de cunho bibliográfico, na categoria autobiográfica. Como resultado do estudo, a proposta pedagógica foi estruturada a partir de uma sequência didática (SD), com gêneros textuais em sala de aula, o que permitiu que os estudantes desenvolvessem habilidades comunicativas, expusessem as suas intenções, argumentassem e tomassem posição consciente e responsável quanto ao seu papel de cidadão, no âmbito da família, da escola e da comunidade. Assim, a prática pedagógica desenvolvida no decorrer do estágio curricular explicitou a relevância do trabalho com gêneros textuais em sala de aula. Suas oportunidades de leitura e escrita, expressão de sentimentos, posicionamento e a constante luta para que os estudantes se reconheçam como cidadão de direitos e deveres na sociedade em que estão inseridos.
\end{abstract}

\begin{abstract}
:
This article refers to an internship practice developed in the last semester of the under graduate course in Literature, Portuguese and Literature - EAD from a Federal University in the South of Brazil, in the year 2020. The theme addressed discusses the relevance of the work with textual genres. In this sense, the objective of this study is to reflect on the pedagogical practice, developed with students of the 3rd year of high school at night, from a State High School, located in the south of Brazil. Such experiences and experiences we seek, answers to the problems of this study: What is the relevance of working with textual genres in the classroom? This study is carried out using as a method an internship practice report passing through the qualitative approach of bibliographic nature, in the autobiographical category. As a result of the study, the pedagogical proposal was structured based on a didactic sequence (SD), with textual genres in the classroom, which allowed students to develop communicative skills, expose their intentions, argue and take a conscious and responsible position. regarding their role as citizens, within the family, school and community. Thus, the pedagogical prac tice developed during the curricular internship made explicit the relevance of working with textual genres in the classroom. Their opportunities for reading and writing, ex pressing feelings, positioning and the constant struggle for students to recognize themselves as citizens with rights and duties in the society in which they are inserted.
\end{abstract}




\section{INTRODUÇÃo}

Este artigo foi elaborado após a conclusão do estágio curricular obrigatório, do último semestre do curso de graduação em Letras, Português e Literaturas - EAD, de uma Universidade Federal da região Sul do Brasil, no ano de 2020. Está narrado em primeiro pessoa, pela cursista Beatriz Fagundes Bica que trouxe suas memórias e experiências pessoais e formativas ao corpo do trabalho, sob o olhar da professora e doutora Cristiane M da Silva Reis. A realização de tal experiência parte do problema: Qual a relevância do trabalho com Gêneros textuais em sala de aula? O período de realização do estágio curricular obrigatório, nas Licen ciaturas, proporciona ao acadêmico o primeiro contato com o seu futuro campo de atuação e a necessidade de contextualizar uma experiência prática, que proporcione a aplicação dos princípios teóricos estudados nas disciplinas da graduação, bem como confrontá-los com a prática pedagógica propriamente dita, o que faz do estágio curricular um importante momento de formação, pois busca proporcionar uma experiência significativa nesta trajetória formativa.

Contudo, nossa formação profissional não ocorre dissociada de nossa formação pessoal, por isso a necessidade de refletirmos sobre os caminhos que nos trouxeram até aqui. Nóvoa nos diz que "[...] ninguém forma ninguém e a formação é inevitavelmente um trabalho de reflexão sobre os percursos da vida”.

A partir dessa citação, refletimos sobre nossa trajetória, sobre os caminhos que trilhamos em busca de nossa formação, que mais do que profissional, é nossa formação pessoal. Estas linhas aqui redigidas, representam muito mais que uma síntese da prática de um Estágio Final do curso de Letras de uma faculdade pú blica renomada como a UFSM (Universidade Federal de Santa Maria).

As experiências vividas durante a construção da minha personalidade, que me levaram a constituição do sujeito que julgo ser, um ser humano capaz de entender que afetividade é essencial no processo educativo e que sem ela não se aprende nem se ensina, me permitem chegar ao espaço-tempo de estágio, com um olhar sensibilizado em relação ao outro. Através desse olhar sensível, percebi diversas histórias que queriam ser contadas, as mais diferentes narrativas de vida: Jovens que trabalham durante o dia e buscam no ensino noturno uma oportunidade de continuar seus estudos, donas de casa, mães, senhoras de mais idade que retomam os estudos após ter a vida um pouco mais organizada, ex-presidiário que busca (re)construir a sua traje tória de vida, adolescentes viciados em drogas ilícitas que buscam no espaço da escola, alguém que os ouça, que os incentive, que lute por eles.

Como ser humano, precisava ouvi-los, mas como estagiária, precisava ir além da escuta, fazia-se necessário desempenhar a prática pedagógica proposta pela disciplina. Intentando unir a minha vontade pessoal com a atividade acadêmica, fiz a escolha por trabalhar com o componente curricular gêneros textuais, acredi tando que através destes, os alunos poderiam refletir, discutir, ressignificar, colocar no papel os seus anseios mais profundos. Dito isso, explicito o objetivo dessa pesquisa: Qual é a relevância do trabalho com Gêneros textuais em sala de aula?

A metodologia utilizada neste estudo é o método narrativo, sendo consultado no âmbito das narrativas, autores como Bertaux (2010) Narrativas de vida: a pesquisa e seus métodos, Delory Monberger (2014), Biografia e educação: figuras do indivíduo projeto, Reis (2008), As narrativas na formação de professores e na investigação em educação. Na esfera de gêneros e linguagens, a pesquisa está embasada nos estudos de auto res como: Mascuschi. L. A. Produção textual, análise dos gêneros e compreensão Dolz, J. e Schneuwly, B. Gêneros Orais e escritos na escola. 


\section{MEtodologia}

O método narrativo autobiográfico não é uma mera escolha, é o desejo de olhar o caminho percorrido e dar novos significados a ele. Conforme defendido por Bertaux,

A utilização das narrativas se mostra aqui particularmente eficaz, pois essa forma de coleta de dados empíricos se ajusta à formação das trajetórias; ela permite identificar por meio de que mecanismos e processos os sujeitos chegaram a uma dada situação, como se esforçam para administrar essa situação e até mesmo para superá-la (BERTAUX, 2010, p. 27).

Esse método põe em evidência o sujeito, valorizando as suas vivências pessoais e formativas, levando-o a refletir sobre o protagonismo em uma história de vida, a sua própria. Ao revisitar meu passado, deparo-me com uma história de enfrentamento econômico e social, que ressignifica as minhas inquietações no que se re fere às desigualdades sociais existentes à nossa volta e frente à elas, um dos meus papéis no mundo: a educação. Pedagoga por amor, cursei Pedagogia Licenciatura Plena com Habilitação em Orientação e Supervisão, estudos custeados com muita dificuldade. Lamentavelmente não tínhamos na cidade em que morava na época, uma instituição pública de ensino superior para intentarmos uma vaga. A tão sonhada formatura somente se tornou possível através de empréstimo financeiro, mas desistir nunca foi uma opção.

Essa lembrança me leva a citar Josso (2004, p.16) que coloca: “No passado não há somente as coisas que ocorreram, há também todo o potencial que cada indivíduo tem para prosseguir a sua existência de futuro”. Corroboro, minha existência é significada pela persistência e coragem de enfrentar os obstáculos encontrados durante o percurso. Especializei-me em Gestão Escolar, na Universidade Federal de Santa Maria, instituição da qual participo atualmente como pesquisadora no Núcleo de Estudos sobre Memória e Educação CLIO, e como acadêmica do último semestre de Letras - Português e Literaturas EAD.

Este trabalho é oriundo da reflexão sobre a prática de Estágio Supervisionado em Letras - Português e Literaturas EAD, de uma Universidade Federal da região sul do Brasil. O espaço investigativo do mesmo foi uma Escola Estadual pública, da mesma região. A prática foi desenvolvida com alunos do $3^{\circ}$ ano do Ensino Médio - Noturno, após o cumprimento das etapas caracterização escolar, observação das aulas e preparação da sequência didática.

O estudo com narrativas de vida tem se mostrado um diferencial nos espaços de formação, uma vez que possibilita a subjetividade do indivíduo. O "olhar para si” permite reconhecer-se enquanto um sujeito permanentemente em construção, que projeta a sua história, Delory Momberger (2014, p.17) diz que,” ... emerge a consciência da figura do indivíduo - projeto, da pessoa que se percebe no que "está sendo”, no que já não pode mais ser, no que ainda deve se tornar.” Para Bertaux (2010, p. 27) “a utilização das narrativas se mostra aqui particularmente eficaz, pois essa forma de coleta de dados empíricos se ajusta à formação das trajetó rias.” Da mesma forma, Delory-Momberger (2014, p. 33) diz que” o ser humano apropria-se de sua vida e de si mesmo por meio de histórias".

Para Josso (2004, p. 48), tão importante quanto narrarmos as nossas experiências, é refletirmos sobre elas, "vivemos uma infinidade de vivências; estas vivências atingem o status de experiências a partir do momento que fazemos um certo trabalho reflexivo sobre o que se passou e sobre o que foi observado, percebido e sentido”. Já Moita (1995, p. 113), diz que a narrativa “põe em evidência o modo como cada pessoa mobili- 
za seus conhecimentos, os seus valores, as suas energias, para ir dando forma à sua identidade, num diálogo com os seus contextos."

Neste projeto inacabado que somos, nos reinventamos à medida que refletimos a nossa existência. $\mathrm{Cu}$ nha (1997, p. 1) diz que "as pessoas vão contando suas experiências, crenças e expectativas e, ao mesmo tempo, vão anunciando novas possibilidades, intenções e projetos. Às vezes, torna-se até difícil separar o vivido do que está por viver”. Assim, sentimos necessidade de contar, significar e ressignificar experiências importantes de nossas vidas como a prática de Estágio Supervisionado em Letras Português e Literaturas à distância: relevância do trabalho com gêneros textuais.

Para construir a apresentação desse estudo, utilizo o método narrativo autobiográfico, consistindo em um relatório descritivo da prática de estágio realizada no curso. Também é uma pesquisa qualitativa de cunho bibliográfico, baseada em narrativas, que surgem como valiosa forma de expressão, uma vez que “[...] o verbo "contar” (fazer relato de) é aqui essencial: significa que a produção discursiva do sujeito tomou a forma de narrativa” (BERTAUX; DANIEL, 2010, p. 47).

Essa abordagem põe em evidência as relações interpessoais e nos leva a compreender que o sujeito se “molda” em sociedade, a partir das experiências vividas com o outro. Daniel Bertaux (2010, p. 43) nos diz que “[...] seu próprio projeto de vida, decidido em certo momento da existência, não foi elaborado in abstrato dentro de uma consciência isolada, mas foi falado, dialogado, construído, influenciado e negociado ao longo da vida em grupo".

Desse modo, elaboramos uma sequência didática (SD) intentando, a partir dos gêneros textuais, possibi litar as interlocuções e a interação como leitores e produtores de textos. A SD contemplava a temática de Educação e Cidadania e destinava-se a reflexões sobre os direitos e deveres essenciais na vida de cada um e a necessidade de ações coletivas na sociedade. Primava para a conscientização de que a busca do bem comum, do crescimento pessoal e da comunidade é necessária para que cada cidadão, de forma individualizada, saiba que ele é parte fundamental de todo o processo, que não é preciso esperar para que o outro tome uma atitude, que cada ação sua reverbera no bem-estar do outro. Visando a igualdade de condições.

Trabalhamos com diversas charges, trazendo os direitos sociais como educação, saúde, alimentação, trabalho, moradia, entre outros, garantidos pela Constituição Federal de 1988. Fazendo-os refletir, construir e reconstruir opiniões sobre assuntos essenciais à vida em sociedade, através da linguagem de humor e ironia presente nas mesmas. Foram apresentados também, alguns artigos de opinião, entre eles: Afinal de contas, você sabe o que é cidadania? Que aprofundou o conceito de direitos e deveres exercidos pelo indivíduo em sociedade e Cidadania é para todos, que fortaleceu as discussões sobre a necessidade de promovermos a cidadania, nas urnas, no parlamento, na escola, nas ruas, em casa, nas redes sociais, no exemplo nosso de cada dia. Além dos artigos, trabalhamos com a crônica de uma cidadania anunciada e que precisa ser valori zada, que trazia em sua mensagem, que a cidadania é do rico, é do pobre, do miserável, do branco, do negro, do índio, do caiçara, do homossexual, de todas as religiões e crenças, dos portadores de deficiências, dos idosos, enfim, de todo ser humano. Por fim, trabalhamos com o artigo de opinião, que dizia que é necessário reagir contra a causa de todas as desigualdades, que é a ausência de uma educação de qualidade.

No espaço da biblioteca realizou-se uma pesquisa coletiva sobre os capítulos I e II da Constituição Federal, que tange os direitos e deveres individuais e coletivos e direitos sociais. A partir dessa exploração, foram confeccionados dois cartazes para favorecer o entendimento dos deveres e obrigações do indivíduo, no convívio em sociedade. Foi oportunizado também, um debate sobre a temática Educação e Cidadania, neste momento a turma foi dividida em três grupos, de forma que o problema levantado fosse defendido por alguns 
alunos, contestado por outros, e que tivesse um terceiro grupo de estudantes especificamente para julgar as argumentações dos colegas. A produção escrita planejada na SD tratava-se de um artigo de opinião, texto dis sertativo argumentativo, que expusesse o ponto de vista do aluno sobre Educação e/ou Cidadania. Por fim, foi proposta a turma, a construção de um jornal mural para exposição e socialização dos textos produzidos.

\section{RESUltados E Discussões}

Conhecer, mesmo que minimamente a turma, foi o ponto de partida para a realização do planejamento. Para tanto, além das observações realizadas, foi aplicado um questionário investigativo, o qual posteriormente foi tabulado.

Após a análise dos dados coletados, concluiu - se que a turma era composta por estudantes entre 17 e 46 anos, na sua maioria por mulheres, que moram com familiares no mesmo bairro em que a escola está situada. A grande maioria trabalha fora e durante o dia dispõe de pouco ou nenhum tempo para lazer, outros tem como atividade principal, cuidar da casa e dos filhos e, concomitante a isso, como aqueles que só estudam, tem tempo livre para as redes sociais, amigos e música. O rap é o estilo musical preferido, sendo citado tam bém, música popular brasileira, samba e pagode. Quanto aos programas que assistem, foram assinalados séri es e canais no youtube.

Os estudantes dizem não ter o hábito da leitura, contudo, quando questionados sobre os livros preferidos, a grande maioria respondeu que é sobre moda, animes e romance. Quanto às dificuldades específicas da dis ciplina de Língua Portuguesa, os alunos presentes foram “quase” que unânimes, disseram apresentar dificul dade nas questões de ortografia e gramática, produção e interpretação textual, contudo, dizem ter facilidade em aprender ouvindo as explicações da professora em sala, resolvendo os exercícios propostos e realizando discussões entre colegas. Por fim, questionados sobre as atividades práticas que estariam dispostos a participar, citaram os debates, seguido de rodas de conversa e pesquisas.

Essa investigação foi proeminente para o planejamento consciente da sequência didática, pois, sabe-se que é necessário que a proposta pedagógica esteja contextualizada com os interesses do aluno para que a educação seja de fato significativa.

A inserção dos gêneros textuais em sala é de extrema importância para trabalhar o desenvolvimento da linguagem dos alunos. Além disso, especialmente para essa turma, a escolha por trabalhar essa proposta ocorreu pela necessidade de instigar o hábito da leitura aos jovens, que através do questionário diagnóstico realizado no primeiro encontro, responderam não tê-lo e incentivá-los a expressar-se criticamente sobre os mais diversos assuntos da vida cotidiana, tão importante segundo Marcuschi (2008, p.115), "os gêneros textuais são os textos que encontramos em nossa vida diária e que apresentam padrões sociocomunicativos característicos definidos por composições funcionais”. Corroborando com o exposto pelo autor, a BNCC (2018) traz as habilidades por campo de atuação no componente língua portuguesa do ensino médio:

\footnotetext{
São demandas que exigem que as escolas de Ensino Médio ampliem as situações nas quais os jovens aprendam a tomar e sustentar decisões, fazer escolhas e assumir posições conscientes e reflexivas, balizados pelos valores da sociedade democrática e do estado de direito. Exigem ainda possibilitar aos estudantes condições tanto para o adensamento de seus conhecimentos, alcançando maior nível de teorização e análise crítica, quanto para o exercício contínuo de práticas discursivas em diversas linguagens. Essas práticas visam à participação qualificada no mundo, por meio de argumentação, formulação e avaliação de propostas e tomada de decisões orientadas pela ética e o bem comum (BNCC, 2018, p. 477).
} 
Assim, o trabalho com gêneros textuais em sala de aula permite que os estudantes desenvolvam habilidades comunicativas, exponham as suas intenções, argumentem e tomem posição consciente e responsável quanto ao seu papel de cidadão, no âmbito da família, da escola e da comunidade.

A proposta pedagógica foi estruturada a partir de uma sequência didática (SD), que segundo Dolz e Schneuwly (2004, p.53) são atividades sistematizadas que "procuram favorecer a mudança e a promoção dos alunos ao domínio dos gêneros e das situações de comunicação”. Nesta, a temática abordada foi educação e cidadania e o objetivo, muito além de expressar-se por escrito com eficiência e de forma adequada a diferentes situações comunicativas ou despertar o interesse pela correção ortográfica e gramatical, era oportunizar momentos de fala, de expressão e reflexão para sujeitos que encontram-se calados. Plantar uma sementinha de esperança, na busca de fazê-los acreditar que eles podem (re)começar a cada novo dia, dispostos a fazer diferente. Contudo, falar de educação e cidadania para sujeitos que se sentem menosprezados por uma camada social dominante é desafiador.

O momento do debate me fez perceber que grande parte dos alunos desconhecem o conceito de democracia e, para os que compreendem, nem mesmo o espaço escolar no qual estão inseridos é democrático. Se referindo a Constituição Federal, o grupo que contestava o debate expôs a opinião de que fora dos sonhos, trata-se apenas de um livro e que a tão sonhada igualdade de condições é um discurso bonito, que na prática não funciona. Para exemplificar esse argumento, citaram a história de vida do colega que foi preso por tráfico, cumpriu pena e busca novas oportunidades de vida, o que é impossível em uma sociedade como a que vivemos. Trata-se de uma narrativa que comoveu à todos. Em meio ao debate, o senhor tomou a palavra e contou-nos que quando traficava tinha tudo que queria e vivia com luxo em uma casa enorme, toda mobiliada, churrasco e cerveja praticamente todo dia. Parentes, mulheres e amigos o visitavam regularmente, mas quando caiu no poço, se referindo a prisão, ninguém demonstrou importar-se com ele. Sofreu muito durante o tempo em que passou recluso, passou maus tratos e foi submetido a um tratamento de saúde extremamente forte e desnecessário, que segundo ele, aconteceu porque os superiores responsáveis pelo presídio acharam que estivesse enlouquecendo. Conclui sua fala dizendo que tem sido muito difícil conviver com a realidade e que o passado continua batendo à sua porta. As pessoas muitas vezes esquecem que ele tem um nome, é o ex-detento, sem casa, sem parentes, sem companheira, sem amigos. Não consegue sequer um emprego for mal que lhe garanta uma vida minimamente digna.

Nas produções escritas foram múltiplos os argumentos sobre igualdade de condições, um dos mais impactantes dizia que a classe média alta pode cometer qualquer crime e sairá impune porque tem dinheiro para pagar advogados e até mesmo subornar juízes, já a população mais vulnerável, se cometer um pequeno deslize será julgada e condenada porque alguém tem que ser, então que seja o pobre. Outra escrita muito relevante fazia menção aos direitos do cidadão como saúde, moradia, alimentação e educação, negligenciados pelos homens de colarinho branco, conforme termo utilizado. Demonstrava indignação sobre as horas em que uma pessoa fica na fila, aguardando atendimento no sistema único de saúde (SUS) ou até dias esperando um leito no hospital quando há a necessidade de internar. Outra escrita expressiva referia-se a falta de políticas públicas voltadas ao atendimento das pessoas que não tem abrigo e moram na rua, sujeitas a todo tipo de violência; aos cidadãos desempregados que não tem condições de alimentar a si e sua família e a educação pública tão precária, que não garante um ensino de qualidade para que os estudantes possam concorrer a uma vaga no Enem com as mesmas condições dos estudantes de escolas privadas.

Através dos relatos e textos produzidos, percebe-se a descrença dos alunos em relação à garantia dos direitos sociais amparados pela Constituição Federal e observa-se que os mesmos se sentem excluídos social- 
mente, principalmente por questões raciais e econômicas. Para os estudantes, as pessoas brancas e de maior poder aquisitivo, impõem o seu jeito e sua maneira de viver, dominando os negros e os menos favorecidos. As classes mais baixas, formadas em sua maioria por serventes, moradores de rua, vigias, faxineiras, ambulantes; quando não, desempregados, não ganham dinheiro suficiente muitas vezes para as necessidades bási cas, como a alimentação e a saúde, muito menos para lazer e entretenimento. Enquanto isso, os ricos acumulam patrimônios e desfrutam de uma vida regada a viagens, carros, mansões, iates. Para esses estudantes, a sociedade é desigual e acreditar na igualdade de condições entre os sujeitos, é utopia.

\section{CONSIDERAÇÕES FINAIS}

Ao discutirmos sobre o reconhecimento e a garantia do pleno desenvolvimento da cidadania, previstos na legislação, estamos falando, especialmente, do direto de ingressar na escola e nela, exercitar sua cidadania. Nesse sentido, o presente estudo argumenta a necessidade de um olhar mais humanizado às práticas escolares. Almeja-se um planejamento que proporcione ao educando expressar-se criticamente, opinar, debater e decidir, pois estes são processos de troca que não se limitam a um espaço ou período de tempo, eles ex trapolam a sala de aula a partir do conhecimento, da vivência de cada um, eliminando as desigualdades sociais, todos tendo os mesmos direitos e recebendo as mesmas oportunidades diante da vida, modificando assim, valores e padrões.

Acredita-se que para uma educação significativa é imprescindível que os estudantes percebam a instituição escolar como espaço democrático, que busca analisar problemas sociais e contribuir para a sua solução, por meio da prática concreta dos educandos e de toda comunidade escolar, que não só assume um papel fundamental no processo de reprodução social, mas é também o cerne da reprodução das relações sociais e da própria estruturação social.

Dessa forma, a prática pedagógica desenvolvida no decorrer do estágio curricular explicitou a relevância do trabalho com gêneros textuais em sala de aula, pelas oportunidades de leitura e escrita, de expressão de sentimentos, de posicionamento, de luta, para que se reconheçam como cidadão de direitos e deveres na sociedade em que estão inseridos, daí a necessidade de abordarmos cada vez mais em nossos planejamentos temas transversais que possam ir ao encontro do estudante, impactando diretamente na sua formação.

Ademais, para que a escola cumpra com o seu papel na sociedade, as relações que se estabelecem dentro e fora dela, devem partir de um olhar para as necessidades individuais do aluno, para as condições em que vivem, as classes sociais a que pertencem, os valores que cultivam entre outras questões que devem ser entendidas e amparadas para que o espaço escolar seja um lugar para o exercício de uma educação cidadã, um espaço onde as particularidades coabitem respeitando-se e entendendo-se, um espaço onde se estimule a afetividade, a construção de elos que melhorem as relações sociais e preparem o indivíduo para o despertar crítico, a fim de ajuda-lo na superação de conflitos.

As narrativas dos estudantes nos fazem perceber que suas vivências e experiências são trazidas para o espaço escolar e são ressignificadas à medida que estes se permitem dialogar e refletir sobre elas. Não tratase de uma tarefa fácil, muito pelo contrário, para expor angústias, inquietações, descrenças, medos, fracassos é preciso muita coragem, por isso, esta narrativa representa não só um olhar à prática pedagógica propriamente dita, e aqui avaliada e (re)construída na interação com o outro mas, especialmente, um olhar aos sujei tos a quem dela se apropriaram. 
Por fim, lanço um olhar sobre mim mesma, me (re)afirmando como pessoa e profissional em formação contínua, buscando na experiência com o outro, aprender e ensinar, trocar e compartilhar, humanizar e humanizar-me, motivar e (auto)motivar-me para estar sempre comprometida com a reflexão/ação necessários à prática pedagógica e o processo de mudança na sociedade em que vivemos.

\section{REFERÊNCIAS}

BERTAUX, Daniel. Narrativas de vida: a pesquisa e seus métodos/tradução Zuleide Alves Cardoso Cavalcante, Denise Maria Gurgel Lavallée; revisão científica Maria da Conceição Passeggi- Natal, RN: EDUFRN, São Paulo: Paulus, 2010.

BRASIL, Constituição (1988). Constituição da República Federativa do Brasil. Brasília, DF: Senado, 1988.

BRASIL, Lei n. 9.394 de 20 de dezembro de 1996. Lei de Diretrizes e Bases da Educação. Brasileira.

CUNHA, Maria Isabel da. Conta-Me Agora!: As Narrativas como Alternativas Pedagógicas na Pesquisa e no Ensino. Rev. Fac. Educ., São Paulo, v. 23, n. 1 - 2 Jan. 1997.

DELORY-MOMBERGER, Christine. Biografia e educação: figuras do indivíduo projeto. $2^{\text {aE} E d i c ̧ a ̃ o . ~ E d i t o r a ~ d a ~ U n i-~}$ versidade Federal do Rio Grande do Norte. 2014

DOLZ, J.; NOVERRAZ, M.; SCHNEUWLY, B. Sequências didáticas para o oral e a escrita: apresentação de um procedimento. In: SCHNEUWLY, B.; DOLZ, J. (Orgs.). Gêneros orais e escritos na escola. Campinas: Mercado de Letras, 2004.

JOSSO, M. C. Experiências de vida e formação. São Paulo: Cortez, 2004.

MOITA, M. C. Percursos de Formação e de Trans-Formação. lu NÓVOA, A Vida de Professores. Porto: Porto Editora, 1995.

REIS, P. R. As narrativas na formação de professores e na investigação em educação. Nuances: Estudos sobre Educação, 15(16), 17-34, 2008.

MASCUSCHI, Luiz Antônio. Produção textual, análise dos gêneros e compreensão. São Paulo: Parábola, 2008. 